\title{
Hepatitis E update
}

\author{
Fulya Gunsar \\ Department of Gastroenterology, Ege University Faculty of Medicine, Izmir, Turkey
}

\begin{abstract}
Hepatitis E virus (HEV) infection is estimated to be one of the commonest causes of acute hepatitis in the world. All patients with symptoms consistent with acute hepatitis should be tested for HEV. HEV was thought to be limited to certain developing countries until the last decade and was only ever seen in travellers of developed countries in returning from hyperendemic countries. We now know that HEV could be endemic in most high-income countries and is largely a zoonotic infection. European Association for the Study of the Liver suggests testing for hepatitis E in patients with unexplained flares of chronic liver disease. Particular risk groups for a severe HEV course are pregnant women infected with genotype 1 and older men or patients with underlying chronic diseases for genotype 3. Prevention is the most important point (safe water, avoiding undercooked meat, to be careful in highly endemic countries) to decrease the HEV infection.
\end{abstract}

Keywords: Acute; chronic; hepatitis E.

\section{Introduction}

Hepatitis E virus (HEV) infection is usually presented as acute hepatitis. HEV is estimated to be one of the commonest causes of acute hepatitis in the world. World Health Organization estimates that there are approximately 20 million HEV infections worldwide per year. ${ }^{[1,2]} \mathrm{HEV}$ infection causes a clinically identifiable acute liver injury in 3.5 million patients and approximately 56.000 deaths/per year. ${ }^{[3,4]}$

Our knowledge of HEV has changed completely in the last ten years. Previously, HEV was thought to be limited to certain developing countries and was only ever seen in travellers of developed countries in returning from hyperendemic areas in Asia or Africa. We now know that HEV could be endemic in most high-income countries and is largely a zoonotic infection, with pigs as the primary host. ${ }^{[1,2,5]}$

Khuroo et al. ${ }^{[6]}$ first identified HEV as an unknown non-A, non-B virus during an outbreak of jaundice in the winter of 1978-1979 in Kashmir. Then, a Russian army doctor provided the first evidence of fecal-oral transmission of this virus by the ingestion of diseased soldiers' stool. This new virus was detected in his stool by electron microscopy. The viral genome was cloned and named HEV in 1980. [1] The median incubation period is 40 days. The majority of patients infected with HEV are asymptomatic. However, HEV infection also causes fulminant hepatic failure, acute or chronic hepatitis. HEV in-

Received: January 06, 2020; Accepted: January 07, 2020; Available online: January 20, 2020

Corresponding author: Fulya Gunsar; Ege Universitesi Tip Fakultesi, Gastroenteroloji Anabilim Dali, 35100 Bornova, Izmir, Turkey Phone: +90 23234277 64; e-mail: fgunsar@yahoo.com

(C) Copyright 2020 by Hepatology Forum - Available online at www.hepatologyforum.org fection is associated with high maternal and fetal mortality during pregnancy. ${ }^{[1]}$

Transmission of the HEV may occur through contaminated food and water, undercooked meat, blood transfusions, and through mother-tochild transmission. Although human-to-human transmission is rare, patients are infectious during the detection of HEV in the stool. Pork must be cooked for more than five minutes at $70^{\circ} \mathrm{C}$ against the risk of HEV virus. ${ }^{[7]}$ Human-to-human transmission (of Genotype 3 and 4) appears restricted to blood transfusion and organ transplantation. Specific genotypes differ in their route of transmission. Approximately up to 1/1000 blood donations in Europe tests positive for HEV. Thus, many European countries decided to test blood donations regularly for $\mathrm{HEV}$ to avoid HEV transmission from blood products. ${ }^{[8]}$

\section{Virology}

HEV belongs to the Hepeviridae, a diverse family of viruses infecting mammals, birds and fish. HEV is a small quasi-enveloped, (+)-sense, single-stranded RNA virus. HEV is approximately 27 to $34 \mathrm{~nm}$ in diameter. Virus excreted in bile and stool is nonenveloped; however, quasi-enveloped forms of HEV exist in the blood, with virions wrapped in membranes derived from infected cells. HEV has a 7.2-kb genome, which encodes three open reading frames (ORFs). ${ }^{[9,10]}$

ORF1 is the largest viral gene product, encoding the replicative machinery of the virus, including the enzymes (methyltransferase, NA helicase, and RNA-dependent RNA polymerase.)

ORF2 is the viral capsid essential for the formation of infectious particles.

ORF3 is a small protein essential for viral release.

Strains of HEV infecting humans belong to the Orthohepevirus genus, which is divided into four species (A-D). Human cases of hepatitis $\mathrm{E}$ arise from strains within species A. It has eight genotypes. G1 to G4 cause human infection. Genotypes 5 and 6 are only for animals. In addition, Genotype 7 and 8 are pathogens for dromedary and Bactrian camels. G1, G2 are responsible for water-borne human outbreaks in developing countries (G1 in Asia and Africa; G2 in Mexico and Africa) G3 and G4 are the zoonotic genotypes (G3 in the West, G4 in Asia) are mainly transmitted by ingestion of undercooked pork in industrialized nations. ${ }^{[11-13]}$

Clinical courses of HEV infection are different according to genotypes. Genotype 1 and 2 infection may cause acute illness (with a high mortality rate of $20 \%$ in pregnant women.) as acute liver failure or acute on chronic liver failure (ACLF). The majority of HEV Genotype 3 and 4 infections have a clinically asymptomatic course and only rarely lead to ACLF in old or patients with chronic liver disease. Immunosuppressed individuals infected with Genotype 3 or 4 may develop chronic hepatitis E, which then may lead to cirrhosis. 


\section{Epidemiology}

The prevalence rates of hepatitis E antibody are higher in developing countries as compared with developed countries ( 10 to 70 versus 1 to 21 percent). The highest prevalence is in Asia and Africa. These high rates were related outbreaks of HEV due to consumption of contaminated drinking water in these areas..$^{[14,15]}$

Anti-HEV immunoglobulin G (IgG) seroprevalence rates of up to $30 \%$ in Germany and higher in France and the Netherlands have been reported. We cannot know if this is a true rise or growing awareness. However, we can say that HEV infection is also quite high in the West more than known before. ${ }^{[16]}$

In Germany, the United Kingdom and France, there have been more reported cases of acute hepatitis E than of HAV or acute HBV infections in 2015-16. ${ }^{[14]}$ The risk of HEV exposure in the United States of America (USA) is nearly two times higher than the risk in neighboring Latin American countries. However, rates of HEV exposure appear to be declining in the USA. ${ }^{[17]}$

In our country, the seroprevalence of HEV was detected as $6.3 \%{ }^{[18]}$ HEV infection was higher in the $3^{\text {rd }}-4^{\text {th }}$ decades and older age had been determined as an independent risk factor for HEV seropositivity in a meta-analysis (seropositivity was highest in the Southeastern Anatolia region). ${ }^{[19]}$

\section{Diagnosis}

The diagnosis of HEV should be considered in patients who present with acute or chronic hepatitis that cannot be explained by other causes. Gold standard for confirming HEV remains detecting the virus in biological samples via polymerase chain reaction (PCR). The presence of IgM anti-HEV antibodies is suggestive of recent HEV infection. The virus is detectable in the stool a week before symptoms begin and remains detectable for up to six weeks; the window for detection in the serum is shorter than that time interval. ${ }^{[2,5]}$ An undetectable viral RNA load does not rule out recent HEV infection. Direct viral detection has particular importance in patients on immunosuppressive medications. Anti-HEV IgM seropositivity antedates the apperance of IgG, peaking at the same time as the highest ALT levels and continues up to 5 months after the disease onset. On the other hand, IgG antibodies appear after IgM but may last beyond a year or sometimes disappear before the first year. ${ }^{[20]}$

HEV infection should be kept in mind in patients under the risk of developing rapidly progressive liver disease, such as pregnant women, patients with chronic liver disease, solid organ transplant recipients, and patients with hematologic malignancies. ${ }^{[21]}$

Clinical presentations are subclassified to three groups as 1. Acute hepatitis 2. Chronic hepatitis 3. Extrahepatic manifestations.

\section{Acute Hepatitis}

The presentation of acute hepatitis was summarized in three groups as immunocompetent people, immunocompromised patients and pregnants. ${ }^{[5]}$

\section{Acute Hepatitis in the Immunocompetent People}

Acute HEV infection is silent and self-limiting in the vast majority. If it manifests clinically, acute HEV infection presents as the other viral hepatitis. Tropical and endemic variants of the disease (G1 and G2) are associated with a more aggressive biochemical and clinical picture of acute hepatitis than those infected with G3 or G4. Progression to fulminant liver failure is rare.

Since the majority of acute HEV is silent and has a mild clinical course, patients do not require treatment. Ribavirin has been used to treat cases of severe acute and ACLF due to HEV infection in endemic areas of G1/G2 infection. Treatment of acute HEV G3 infection using ribavirin has also been described. However, recently, there are some cases of ribavirin resistance and treatment failure. ${ }^{[5,22]}$

\section{Acute Hepatitis in the Immunocompromised Patients}

Acute HEV infection usually presents asymptomatically. The symptomatic patients have jaundice, fatigue, diarrhoea and myalgia. Prolonged cholestasis, with protracted jaundice (lasting $>3$ months), has been described in up to 60 percent of patients with acute HEV. Patients may have symptoms of pruritus due to cholestasis. ${ }^{[23]}$ The necroinflammatory T-cell mediated immune response, in HEV infection, is more aggressive in the immunocompetent individuals. Therefore, serum transaminase activity is higher in immunocompetent individuals ( $>1000 \mathrm{IU} / \mathrm{L})$ than in the immunosuppressed patients (100-300 IU/L range). ${ }^{[24]}$

Careful monitoring of HEV RNA levels, serology and hepatic enzyme activity are essential for the management of acute hepatitis. Given that a significant number of patients will clear the virus spontaneously, specific treatment or immunosuppressant reduction is not necessary. ${ }^{[1]}$ The reduction of immunosuppressive therapy is often sufficient in moderate or severe cases. ${ }^{[1,25]}$ If HEV infection presents with extrahepatic manifestations, British Transplant Society (BTS) guidelines recommend early treatment with ribavirin. ${ }^{[25]}$

\section{Acute Hepatitis During Pregnancy}

Acute hepatitis E during the third trimester is associated with devastating maternal and fetal outcomes. ${ }^{[22]}$ The pregnant women infected with genotype 1 (but also other genotypes) are the most important risk group for a severe HEV course. ${ }^{[5]} \mathrm{HEV}$ infections are associated with eclampsia gravidarum, hemorrhagic complications and liver failure. The reasons for fatal courses in pregnancy are still not clearly understood. Hormonal, immunological and genetic factors could be effective. Pregnant women with acute viral hepatitis $\mathrm{E}$ have had worse prognosis for the mother and fetus compared to hepatitis B or C in a study from India. ${ }^{[26]}$ Management of these patients is primarily supportive treatment. However, a recombinant protein-based vaccine has been found to be safe and effective in phase 2 and phase 3 trials in China. ${ }^{[27]}$

\section{Chronic Hepatitis}

Chronic HEV infection is defined as the detection of HEV RNA in serum or stool for longer than six months. Although few reports of immunocompetent individuals developing chronic HEV infection have been published, ${ }^{[28,29]}$ chronic form is primarily described in patients with immunodeficiency.

Immunosuppressed patients with chronic HEV may rapidly progress to end-stage liver disease (even within 1 year after HEV infection). Between 46 and $80 \%$ of the solid organ transplant recipients cannot clear the virus spontaneously and are under the risk of chronicity. ${ }^{[24,30]}$ The incubation period is longer than seen in immunocompetent hosts at 60 days.

There are some risk factors reported for the development of chronic- 


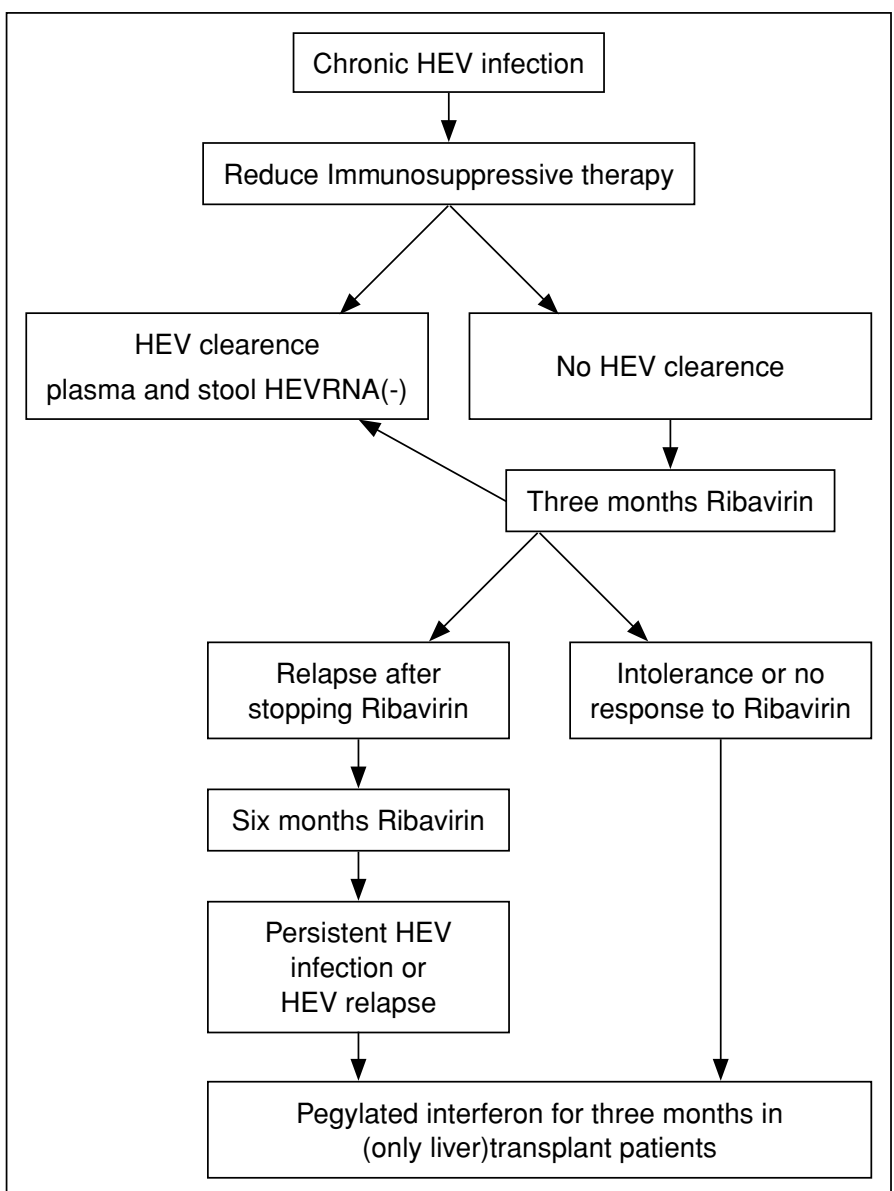

Figure 1. Treatment algorithm for the chronic HEV infection for transplant recipients. ${ }^{[1]}$

ity in solid organ transplant recipients, such as using tacrolimus, a low lymphocyte count at diagnosis and liver transplantation. ${ }^{[24]}$

Chronic HEV infection is almost exclusively secondary to HEV G3. One case of chronic HEV G4 infection has been published, but none due to HEV G1 or 2. In some patients with persistent HEV, replication could be both anti-HEV IgG and IgM (-). Therefore, it is mandatory to use nucleic acid amplification techniques for serum, plasma, or stool samples of patients with HEV infection.

In Kamar's study, one-third of 80 solid organ recipients who were infected with HEV infection was symptomatic. Fatigue was the main symptom in these patients. The majority of the patients were asymptomatic. Fifty-six patients $(65.9 \%)$ developed chronic hepatitis. Onethird of patients achieved viral clearance with dose reductions of immunosuppressive therapy. ${ }^{[24]}$ In the rest of the patients, treatment with ribavirin at a median dose of $600 \mathrm{mg} /$ day for three months resulted in a SVR of $78 \%$.

In Chauhan's study, over half (55\%-20/36 patients) solid organ recipients with HEV infection cleared HEV by the reduction of immunosuppressive therapy. The other 16 patients were treated with ribavirin. Onefourth of these patients had treatment failure and needed the second course of ribavirin therapy. ${ }^{[5]}$

According to European Association for the Study of the Liver (EASL) and BTS guidelines, the first choice for treatment of HEV infection in solid organ transplant recipients is the reduction of immunosuppresive therapy. ${ }^{[1,25]}$ Patients with severe liver dysfunction or viral persistence for more than three months despite a reduction in immunosuppression need further treatment. In this condition, ribavirin $(600-1000 \mathrm{mg} / \mathrm{day})$ is the choice. Ribavirin dosage can be set according to haemoglobin levels and kidney functions. Ribavirin treatment lasts between three to six months. Ribavirin can be stopped if the HEV RNA is negative in the sera and stool at week 12. If HEV is detectable in serum and/ or stools at week 12, ribavirin therapy should be extended for an additional 12 weeks. Sustained virologic response (SVR) is determined as the negativity of HEV RNA by PCR 12 weeks after the cessation of treatment (Fig. 1). ${ }^{[5,25]}$

\section{Treatment for Relapsers}

The relapse after three months of RBV therapy should be treated with a longer 6-month course of ribavirin (EASL guidelines.) The majority of relapsers achieved SVR after six months of RBV monotherapy. In cases of treatment failure, after completion of ribavirin therapy, EASL suggests a trial of pegylated IFN for three months in liver transplant recipients. Pegylated interferon is, however, contraindicated in heart, lung, kidney and pancreas transplant recipients related to the risk of acute rejection (Fig. 1). ${ }^{[1,5]}$

\section{Acute on Chronic Liver Failure}

Acute HEV infection in patients with chronic liver disease may result in ACLF. HEV G3 in an European cohort of patients, have similar outcome concerning mortality compared to other causes of ACLF. HEV G1 or G2 reveals a far worse outcome in China and the Indian subcontinent. Mortality was reported as up to $70 \%$ (with a median of $34 \%$ ). Over a fifth of all cases of ACLF in Asian countries are due to acute HEV infection. ${ }^{[1,5]}$ Patients with G4 hepatitis E are at high risk to develop $A(C) L F .{ }^{[31]}$ BTS suggest the early use of ribavirin in patients with end stage liver disease awaiting liver transplantation. ${ }^{[25]}$

\section{Extrahepatic Manifestations}

HEV may cause acute pancreatitis, neurological and renal diseases. Neurological diseases can be as post-infectious polyradiculoneuropathy (Guillain Barré syndrome), neuralgic amyotrophy (postinfectious and immune mediated), meningoencephalitis (direct neurotoxic effect of the virus) due to G1 and G3 HEV. Renal diseases can be membranous GN, membranoproliferative GN and even relapses of IgA nephropathy due to mainly G3 sometimes G1. ${ }^{[1,5]}$ Comprehensive data accurately defining the management of extrahepatic HEV are currently lacking. BTS suggest early treatment with ribavirin in these patients with extrahepatic manifestations. ${ }^{[25]}$

\section{Prevention from HEV Infection}

Prevention is the most important issue against HEV infection. We must maintain quality standards for public water supplies for particularly drinking water. Handwashing with safe water before eating or handing any food is the first step. Avoiding uncooked shellfish, vegetables and fruits were prepared by people in highly endemic countries is another major issue for prevention. Eating undercooked pork is risky behavior for Western countries. Although a prophylactic vaccine for HEV has been developed, it is only licensed in China, this vaccine is effective against HEV genotypes 1 and 4. ${ }^{[27]}$ 
In conclusion, all patients with symptoms consistent with acute hepatitis should be tested for HEV. EASL suggests testing for hepatitis E in patients with unexplained flares of chronic liver disease. Particular risk groups for a severe HEV course are pregnant women infected with genotype 1 and elderly men or patients with underlying chronic diseases for genotype 3 . Prevention is the most important point (safe water, avoiding undercooked meat, to be careful in highly endemic countries) to decrease the HEV infection.

Peer-review: Externally peer-reviewed.

Conflict of Interest: The author have no conflict of interest to declare.

Financial Disclosure: The author declared that this study has received no financial support.

\section{References}

1. European Association for the Study of the Liver. EASL Clinical Practice Guidelines on hepatitis E virus infection. Journal of Hepatology 2018,68:1256-1271.

2. Horvatits T, Schulze Zur Wiesch J, Lütgehetmann M, Lohse AW, Pischke S. The clinical perspective on Hepatitis E. Viruses 2019;11(7). pii: E617.

3. Bazerbachi F, Haffar S, Garg SK, Lake JR. Extra-hepaticmanifestations associated with hepatitis $\mathrm{E}$ virus infection: a comprehensive review of the literature. Gastroenterol Rep (Oxf) 2016;4(1):1-15.

4. Hoofnagle JH, Nelson KE, Purcell RH. Hepatitis E. N Engl J Med 2012;367(13):1237-1244.

5. Chauhan A, Webb G, Ferguson J. Clinical presentations of Hepatitis E: A clinical review with representative case histories. Clin Res Hepatol Gastroenterol 2019;43(6):649-657.

6. Khuroo MS. Study of an epidemic of non-A, non-B hepatitis: possibility of another human hepatitis virus distinct from post-transfusion non-A, non-B type. Am J Med 1980;68(6):818-824.

7. Imagawa $\mathrm{T}$, Sugiyama R, Shiota $\mathrm{T}$, Li TC, Yoshizaki S, Wakita T, et al. Evaluation of heating conditions for inactivation of hepatitis e virus genotypes 3 and 4. J. J Food Prot 2018;81(6):947-952.

8. Westhölter D, Hiller J, Denzer U, Polywka S, Ayuk F, Rybczynski M, et al. Hev-positive blood donations represent a relevant infection risk for immunosuppressed recipients. J Hepatol 2018;69(1):36-42.

9. Johne R, Dremsek P, Reetz J, Heckel G, Hess M, Ulrich RG. Hepeviridae: an expanding family of vertebrate viruses. Infect Genet Evol 2014;27:212229.

10. Johne R, Reetz J, Ulrich RG, Machnowska P, Sachsenröder J, Nickel P, et al. An ORF1-rearranged hepatitis E virus derived from a chronically infected patient efficiently replicates in cell culture. J Viral Hepat 2014;21(6):447456.

11. Xia J, Zeng H, Liu L, Zhang Y, Liu P, Geng J, et al. Swine and rabbits are the main reservoirs of hepatitis E virus in China: detection of HEV RNA in feces of farmed and wild animals. Arch Virol 2015;160(11):2791-2798.

12. Woo PC, Lau SK, Teng JL, Tsang AK, Joseph M, Wong EY, et al. New hepatitis E virus genotype in camels, the middle east. Emerg Infect Dis 2014;20(6):1044-1048.
13. Smith DB, Simmonds P, Izopet J, Oliveira-Filho EF, Ulrich RG, Johne R, et al. Proposed reference sequences for hepatitis E virus subtypes. J Gen Virol 2016;97(3):537-542.

14. Aggarwal R. Hepatitis E: Historical, contemporary and future perspectives. J Gastroenterol Hepatol. 2011;26(Suppl 1):72-82.

15. Kmush B, Wierzba T, Krain L, Nelson K, Labrique AB. Epidemiology of hepatitis E in low- and middle-income countries of Asia and Africa. Semin Liver Dis 2013;33(1):15-29.

16. Hartl J, Otto B, Madden RG, Webb G, Woolson KL, Kriston L, et al Hepatitis E seroprevalence in Europe: A meta-analysis. Viruses 2016;8(8).

17. Horvatits T, Ozga AK, Westhölter D, Hartl J, Manthey CF, Lütgehetmann $\mathrm{M}$, et al. Hepatitis E seroprevalence in the americas: A systematic review and meta-analysis. Liver Int 2018;38(11):1951-1964.

18. Aydın NN, Ergünay K, Karagül A, Pınar A, Us D. Hacettepe Üniversitesi Tip Fakültesi Hastanesine Başvuran Olgularda Hepatit E Virusu Seroprevalansının Araştırılması* Mikrobiyol Bul 2015;49:554-556.

19. Leblebicioglu H, Ozaras R. Hepatitis E virus infection in Turkey: a systematic review. Ann Clin Microbiol Antimicrob 2018;17(1):17.

20. Arends JE, Ghisetti V, Irving W, Dalton HR, Izopet J, Hoepelman AI. Hepatitis E: an emerging infection in high income countries. J Clin Virol 2014;59(2):81-88.

21. Pawlotsky JM. Hepatitis E screening for blood donations: an urgent need? Lancet. 2014;384(9956):1729-1730.

22. Donnelly MC, Scobie L, Crossan CL, Dalton H, Hayes PC, Simpson KJ. Review article: hepatitis E-a concise review of virology, epidemiology, clinical presentation and therapy. Aliment Pharmacol Ther 2017;46(2):126-141.

23. Mechnik L, Bergman N, Attali M, Beergabel M, Mosenkis B, Sokolowski N, et al. Acute hepatitis $\mathrm{E}$ virus infection presenting as a prolonged cholestatic jaundice. J Clin Gastroenterol 2001;33(5):421-422.

24. Kamar N1, Garrouste C, Haagsma EB, Garrigue V, Pischke S, Chauvet C, et al. Factors associated with chronic hepatitis in patients with hepatitis $\mathrm{E}$ virus infection who have received solidorgan transplants. Gastroenterology 2011;140(5):1481-1489.

25. McPherson S, Elsharkawy AM, Ankcorn M, Ijaz S, Powell J, Rowe I, et al. Summary of the British transplantation society UK guidelines for hepatitis E and solid organ transplantation. Transplantation 2018;102(1):15-20.

26. Patra S, Kumar A, Trivedi SS, Puri M, Sarin SK. Maternal and fetal outcomes in pregnant women with acute hepatitis E virüs infection. Ann Intern Med 2007;147(1):28-33.

27. Zhang J, Zhao Q, Xia N. Prophylactic Hepatitis E Vaccine. Adv Exp Med Biol 2016;948:223-246.

28. Pischke S, Hardtke S, Bode U, Birkner S, Chatzikyrkou C, Kauffmann W, et al. Ribavirin treatment of acute and chronic hepatitis E: a single-centre experience. Liver Int 2013;33(5):722-726.

29. Grewal P, Kamili S, Motamed D. Chronic hepatitis E inan immunocompetent patient: a case report. Hepatology 2014;59(1):347-348.

30. Kamar N, Rostaing L, Izopet J. Hepatitis E virus infection in immunosuppressed patients: natural history and therapy. Semin Liver Dis 2013;33(1):62-70.

31. Wang Y, Liu H, Liu S, Yang C, Jiang Y, Wang S, et al Incidence, predictors and prognosis of genotype 4 hepatitis E related liver fallure: A tertiary nested case-control study. Liver Int 2019;39(12):2291-2300. 